\title{
Effect of Intra-Uterine Injection of hCG on Implantation Rate in IVF Candidates
}

\author{
Soghra Rabiee (MD) \\ Endometrium and Endometriosis \\ Research Center, Hamadan University \\ of Medical Sciences, Hamadan, Iran \\ Sima Saffari (MD) \\ Department of Obstetrics and \\ Gynecology, Fatemieh Women \\ Hospital, Hamadan University of \\ Medical Sciences, Hamadan, Iran \\ Nazanin Fallah (MD) \\ Department of Anesthesiology, Besat \\ Hospital, Hamadan University of \\ Medical Sciences, Hamadan, Iran \\ Marzieh Farimani (MD) \\ Endometrium and Endometriosis \\ Research Center, Hamadan University \\ of Medical Sciences, Hamadan, Iran \\ Mahnaz Yavangi (MD) \\ Endometrium and Endometriosis \\ Research Center, Hamadan University \\ of Medical Sciences, Hamadan, Iran \\ Corresponding author: Soghra \\ Rabiee \\ Email: rabiei@umsha.ac.ir \\ Tel: +989181111050 \\ Address: Department of Obstetrics \\ and Gynecology, Fatemieh Women \\ Hospital, Hamadan University of \\ Medical Sciences, Hamadan, Iran \\ Received : 20 Jun 2017 \\ Revised: 05 Nov 2016 \\ Accepted: 01 Jun 2017
}

\begin{abstract}
Background and Objectives: Human chorionic gonadotropin (hCG) is the embryonic hormone and one of the most important factors for implantation. The present study aimed to evaluate effect of intra-uterine injection of hCG before embryo transfer on the pregnancy outcome in IVF.

Methods: In this study, 180 infertile patients were randomly allocated into an experiment and a control group. In the experiment group, before embryo transfer, 500 II hCG were injected into the endometrium cavity in puncture stage. Equal amount of phosphate buffer (placebo) was injected to the subjects in the control group. Pregnancy test was done two weeks after the intervention. In case of positive results, ultrasound scan was done for detecting the gestational sac and numbers of sacs.

Results: Mean age of the patients was $30 \pm 3.41$ years and $31 \pm 4.12$ years in the experimental and control group, respectively. There was no statistically significant difference in the duration of infertility between the two groups ( $4.77 \pm 3.67$ years vs. $4.07 \pm 3.74$ years). Based on the hCG level, the pregnancy rate was $35.5 \%$ in both groups. However, based on ultrasound findings, the pregnancy rate was $35.5 \%$ and $20.0 \%$ in the experiment group and the control group, respectively $(\mathrm{P}=0.33)$. In addition, there was no significant difference in the pregnancy rates between different age groups.

Conclusion: 0ur results indicate that the intra-uterine injection of $\beta$-hCG has no significant effect on the pregnancy rate in IVF.

Keywords: Fertilization in Vitro, Chorionic Gonadotropin, Injections.
\end{abstract}




\section{INTRODUCTION}

Implantation refers to a stage of pregnancy in which the embryo adheres and penetrates to the endometrium. Several factors including cytokines, growth factors, adhesion proteins, hormones and enzymes play a critical role in stages of implantation. Change in normal activity of these factors can lead to implantation failure and infertility (1).

One of the fundamental and restrictive stages of successful assisted reproductive technology (ART) cycles is appropriate implantation of embryo, which is associated with both embryo and endometrium (2). Due to effect of some hormones such as estrogen and progesterone, some morphological and biochemical changes occur in the endometrium to provide a suitable environment for the implantation. Estrogen stimulates proliferation of endometrial cells, while progesterone is involved in differentiation of the cells into a secretory phenotype. These hormones function mainly through their nucleus receptors, and result in differentiation of endometrium cells $(3,4)$.

Approximately $75 \%$ of embryos created by in vitro fertilization (IVF) and transferred to uterine will implant. More successful outcomes in such pregnancies require more information about molecular mechanisms involved in endometrial preparation for embryo implantation (5).

In 2006 , only 36,000 of 125,000 IVF cases led to delivery. Concern about the outcome of these pregnancies causes problems in the life and relationship of couples who use these routes of pregnancy (6). It is estimated that 50$75 \%$ of miscarriages are due to implantation failure (7). Moreover, despite the recent clinical and laboratory advancement in IVF procedures, the success rate per each embryo transfer (ET) is only 30\% (7). A safe and inexpensive method of differentiating normal pregnancies from abnormal pregnancies can eliminate couples' psychological distress (8).

In recent studies, human chorionic gonadotropin (hCG) serum level has been suggested as a reliable marker for predicting outcome of IVF pregnancies (8). According to these studies, $\beta$-hCG titer immediately after implantation is associated with the pregnancy outcome (6). This hormone is one of the most important factors in embryo implantation by regulating endometrial receptivity (7). Although growth of human embryo in early stages after implantation is undetectable, hCG measurement can indirectly provide information about embryo development. The hormone can be detected in both mother's urine and serum samples (9). In ART techniques, hCG elevation 16 days after implantation, can be a valuable prognostic endocrine factor for pregnancy diagnosis (10). The hormone also plays a crucial role in pregnancy progression and maintenance. Moreover, hCG is involved in maintenance of corpus luteum, progesterone generation, embryonic implantation, trophoblastic function and regulation of connection between mother and the embryo (11). It has been also claimed that intra-uterine injection of 500 unit hCG before ET can significantly improve implantation and pregnancy rates (7).

Based on recent studies, hCG is secreted in early stages of embryogenesis, and its level correlated with the number of blastomeres and the stage of embryogenesis. Hence, it is suggested that higher secretion of hCG could increase the chance of implantation (12). A study on 180 infertile patients demonstrated that intra-uterus injection of hCG before ET can increase the rate of successful implantation (up to $14.5 \%$ ), pregnancy (14.1\%) and pregnancy stability (up to $13.7 \%$ ) compared to a control group (13). Therefore, the aim of this study was to investigate effect of hCG injection before ET in IVF candidates at Fatemieh University Hospital during 2016.

\section{MATERIAL AND METHODS}

This clinical trial (registered at Iranian Registry of Clinical Trials, code: IRCT201510079014N81) was performed in Endometrium and Endometriosis Research Center of Hamadan University of Medical Sciences at Fatemieh University Hospital (Hamedan, Iran) on 180 infertile patients. The subjects were randomly and equally divided into an experiment and a control group. Inclusion criteria were as follow: age $<40$ years, infertility due to male factor, no use of OCP or other hormonal contraceptives and willingness to participate in the study. In the case group, $500 \mathrm{IU}$ hCG were injected in the endometrium cavity in puncture stage before ET. Phosphate buffer (placebo) was injected into the uterine of subjects in the control group. Pregnancy test was done two weeks after the intervention for detection of hCG level. In case of positive results, ultrasound 
scan was done for detecting the gestational sac and numbers of sacs.

Written informed consent was taken from all participants in the study. The study has been approved by the Research Ethics Committee of the Hamadan University of Medical Sciences (Code: IR.UMSHA.REC.1394.70). Data of each subject regarding age and duration of infertility were collected. All data were analyzed in SPSS (version 22) using chisquared test.

\section{RESULTS}

Mean age of the subjects was $30 \pm 3.41$ years and $31 \pm 4.12$ years in the experimental and control group, respectively. There was no statistically significant difference in the duration of infertility between the two groups (4.77 \pm 3.67 years vs. $4.87 \pm 3.74$ years). Based on the hCG level, the pregnancy rate was $35.5 \%$ in both groups. However, based on ultrasound findings, the pregnancy rate was $35.5 \%$ and $28.8 \%$ in the experiment group and the control group, respectively $(\mathrm{P}=0.33)$. In addition, there was no significant difference in the pregnancy rate between different age groups.

\section{DISCUSSION}

In recent years, several studies have been conducted on increasing the fertility rate in IVF. Despite the significant advancements achieved in ovulation stimulation and oocyte maturation features, implantation rate in ART is still less than expected. We investigated the effect of hCG injection on implantation rate and ongoing pregnancy. According to our results, the intra-uterine injection of hCG has no considerable effect on improving embryo implantation.

\section{REFERENCES}

1. Dunson DB, Baird DD, Colombo B. Increased infertility with age in men and women. Obstetrics \& Gynecology. 2004; 103(1): 51-6. DOI:10.1097/01.AOG.0000100153.24061.45.

2. Wilcox AJ, Baird DD, Weinberg CR. Time of implantation of the conceptus and loss of pregnancy. New England Journal of Medicine. 1999; 340(23):17969. DOI: 10.1056/NEJM199906103402304.

3. Sharkey AM, Smith SK. The endometrium as a cause of implantation failure. Best practice \& research Clinical obstetrics \& gynaecology. 2003;17(2): 289-307.

4. Bagchi IC, Kumar S, editors. Steroid-regulated molecular markers of implantation. Seminars in reproductive endocrinology. Seminars in Reproductive Endocrinology. 1999; 17(3): 235-240.
According to previous studies, $\beta$-hCG titer immediately after the implantation is associated with pregnancy outcome (14-18). Implantation is a complicated process controlled by various factors, particularly hCG. It has been demonstrated that hCG can initiate and control endometrium invasion for initiation of pregnancy (19).

Physiologic effect of hCG can be observed only in certain doses and period of time, including secretion during embryogenesis and endometrial receptivity during the implantation process (20-23). Different isomers of hCG, such as hyperglycolized hCG and $\beta$-hCG secreted from cytotrophoblast and syncytiotrophoblast, are related to the stage of embryogenesis and implantation (24-26). More studies should be performed on the role of hCG in embryo implantation and methods of improving implantation outcomes in IVF.

\section{CONCLUSION}

Our results indicate that the intra-uterine injection of $\beta$-hCG has no significant effect on the pregnancy rate in IVF.

\section{ACKNOWLEDGEMENTS}

We hereby express our gratitude for the Deputy of Research and Technology of Hamadan University of Medical Sciences and the personnel of Endometriosis Research Center at Fatemieh University Hospital for technical assistance. The study has been financially supported by the Hamadan University of Medical Sciences (project number 9603161739).

\section{CONFLICT OF INTEREST}

The authors declare that there is no conflict of interest.

5. Oehler MK, Rees MC, Bicknell R. Steroids and the endometrium. Current medicinal chemistry. 2000; 7(5): 543-60.

6. Paulson RJ, Sauer MV, Lobo RA. Factors affecting embryo implantation after human in vitro fertilization: a hypothesis. American journal of obstetrics and gynecology. 1990; 163(6): 2020-3.

7. Koot Y, Teklenburg G, Salker M, Brosens JJ, Macklon N. Molecular aspects of implantation failure. Biochimica et Biophysica Acta (BBA)-Molecular Basis of Disease. 2012;1822(12):1943-50.

10.1016/j.bbadis.2012.05.017. 
8. Norwitz ER, Schust DJ, Fisher SJ. Implantation and the survival of early pregnancy. New England Journal of Medicine. 2001; 345(19): 1400-8. DOI:10.1056/NEJMra000763.

9. Cunningham F, Leveno K, Bloom S, Hauth J, Rouse D, Spong C. Implantation, embryogenesis, and placental development: secretory or postovulatory endometrial phase. McGraw-Hill. 2010; 48.

10. Tsampalas M, Gridelet V, Berndt S, Foidart J-M, Geenen V, d'Hauterive SP. Human chorionic gonadotropin: a hormone with immunological and angiogenic properties. Journal of reproductive immunology. 2010; 85(1): 93-8. doi: 10.1016/j.jri.2009.11.008.

11. Homan G, Brown S, Moran J, Homan S, Kerin J. Human chorionic gonadotropin as a predictor of outcome in assisted reproductive technology pregnancies. Fertility and sterility. 2000; 73(2): 270-4.

12. Cole LA. Biological functions of $h C G$ and $h C G-$ related molecules. Reproductive Biology and Endocrinology. 2010; 8(1): 102. doi: 10.1186/14777827-8-102.

13. Lambers MJ, van Weering HG, van't Grunewold MS, Lambalk CB, Homburg R, Schats R, et al. Optimizing hCG cut-off values: a single determination on day 14 or 15 is sufficient for a reliable prediction of pregnancy outcome. European Journal of Obstetrics \& Gynecology and Reproductive Biology. 2006; 127(1): 94-8.

14. Licht P, Fluhr H, Neuwinger J, Wallwiener D, Wildt L. Is human chorionic gonadotropin directly involved in the regulation of human implantation? Molecular and cellular endocrinology. 2007; 269(1-2): 85-92.

15. Makrigiannakis A, Minas V, Kalantaridou SN, Nikas G, Chrousos GP. Hormonal and cytokine regulation of early implantation. Trends in Endocrinology \& Metabolism. 2006;17(5):178-85.

16. Banerjee P, Fazleabas AT. Extragonadal actions of chorionic gonadotropin. Reviews in Endocrine and Metabolic Disorders. 2011; 12(4): 323. DOI:10.1016/j.tem.2006.05.001

17. Cole LA. $h C G$, the wonder of today's science. Reproductive Biology and Endocrinology. 2012; 10(1): 24. doi: 10.1186/1477-7827-10-24.
18. Licht P, Russu V, Wildt L, editors. On the role of human chorionic gonadotropin ( $h C G$ ) in the embryoendometrial microenvironment: implications for differentiation and implantation. Seminars in reproductive medicine. 2001; 584-4662.

19. Edwards R. Chorionic gonadotrophin, genes and embryonic signals regulating the implantation window. Reproductive biomedicine online. 2007;14(4):538-9.

20. Bonduelle M-L, Dodd R, Liebaers I, Van Steirteghem A, Williamson R, Akhurst R. Chorionic gonadotrophin- $\beta$ mRNA, a trophoblast marker, is expressed in human 8-cell embryos derived from tripronucleate zygotes. Hum Reprod. 1988; 3(7): 909-14.

21. Dokras A, Sargent I, Barlow D. Fertilization and early embryology: Human blastocyst grading: an indicator of developmental potential? Hum Reprod. 1993; 8(12): 2119-27.

22. Brosens JJ, Salker MS, Teklenburg G, Nautiyal J, Salter S, Lucas ES, et al. Uterine selection of human embryos at implantation. Scientific reports. 2014; 4: 3894. doi: 10.1038/srep03894.

23. Riboldi M, Barros B, Piccolomini M, Alegretti J, Motta E, Serafini P. Does the intrauterine administration of rhCG before vitrified blastocysts transfer improves the potential of pregnancies when using blastocysts of inferior morphological grading? Fertility and Sterility. 2013; 100(3): S289.

24. Salker M, Teklenburg G, Molokhia M, Lavery S, Trew G, Aojanepong T, et al. Natural selection of human embryos: impaired decidualization of endometrium disables embryo-maternal interactions and causes recurrent pregnancy loss. PloS one. 2010; 5(4): e10287.

25. Paiva P, Hannan N, Hincks C, Meehan K, Pruysers E, Dimitriadis E, et al. Human chorionic gonadotrophin regulates $F G F 2$ and other cytokines produced by human endometrial epithelial cells, providing a mechanism for enhancing endometrial receptivity. Hum Reprod. 2011; 26(5): 1153-62. doi: 10.1093/humrep/der027.

26. Srivastava A, Sengupta J, Kriplani A, Roy KK, Ghosh D. Profiles of cytokines secreted by isolated human endometrial cells under the influence of chorionic gonadotropin during the window of embryo implantation. Reproductive Biology and Endocrinology. 2013; 11(1): 116. 